\title{
Autoimmune Hepatitis in the Asia-Pacific Area
}

\author{
Qi-Xia Wang\#, Li Yan\# and Xiong Ma* \\ Division of Gastroenterology and Hepatology, Key Laboratory of Gastroenterology and Hepatology, Ministry of Health, State Key \\ Laboratory for Oncogenes and Related Genes, Renji Hospital, School of Medicine, Shanghai Jiao Tong University, Shanghai \\ Institute of Digestive Disease, Shanghai, China
}

\begin{abstract}
Autoimmune hepatitis has been considered as a relatively rare immunological liver disease, especially in the Asia-Pacific area. Although the diagnosis criteria and immunosuppressive treatment regimens have been established, there are still some challenges. According to the different presentations, the personalized management of patients who suffer from this disease, including those with chronic or acute severe onset, the autoantibody-negative phenotype and cirrhosis are necessarily descriptive. Each subgroup of patients should receive an individualized therapy. Here, we review the recent studies of autoimmune hepatitis, mainly focusing on the epidemiology and genetics, personalized diagnostics, individualized treatment strategies, special subgroups and outcomes. Most of the research in the literature is based on Japanese and Chinese populations.

Citation of this article: Wang QX, Yan L, Ma X. Autoimmune hepatitis in the Asia-Pacific area. J Clin Transl Hepatol 2018;6(1):48-56. doi: 10.14218/JCTH.2017.00032.

\section{Introduction}

Autoimmune hepatitis (AIH) was first reported in the early 1950 s by the Swedish physician Jan Waldenström, who described a cohort of young women with chronic fluctuating hepatitis accompanied by hypergammaglobulinemia and extra-hepatic manifestations. ${ }^{1}$ In the 1990 s, the comprehensive diagnostic criteria and revised criteria for research purposes were put forward by the International Autoimmune Hepatitis Group (IAIHG) ${ }^{2,3}$ The simplified scoring system, which is easier to use in routine clinical practice, was proposed in 2008, and subsequently validated in variant ethnical groups, including Chinese and Japanese populations. ${ }^{4-9}$ Although most of the previous AIH studies were performed
\end{abstract}

Keywords: Autoimmune hepatitis; Outcome; Personalized management; AsiaPacific area.

Abbreviations: 6-MP, 6-mercaptopurine; ACA, anticentromere antibodies; $\mathrm{AIH}$ autoimmune hepatitis; ALT, alanine aminotransferase; ANA, anti-nuclear antibody; anti-SLA/LP, anti-soluble liver antigen/liver-pancreas antigen; ASMA, antismooth muscle antibody; AST, aspartate aminotransferase; $\mathrm{HBsAg}$, hepatitis $B$ surface antigen; HBV, hepatitis B virus; HCC, hepatocellular carcinoma; HLA, human leukocyte antigen; IAIHG, International Autoimmune Hepatitis Group; IgG, immunoglobulin G; NASH, non-alcoholic steatohepatitis; PBC, primary biliary cholangitis; ULN, upper limit of normal.

Received: 17 May 2017; Revised: 23 September 2017; Accepted: 26 October 2017

"These authors contributed equally to this work.

* Correspondence to: Xiong Ma, Renji Hospital, School of Medicine, Shangha Jiao Tong University, Shanghai Institute of Digestive Disease, 145 Middle Shandong Road, Shanghai 200001, China. Tel: +86-21-63200874, Fax: +86-2163266027, E-mail: maxiongmd@163.com in Europe and Northern America, more and more investigations from eastern countries have been reported in the past 10 years. ${ }^{10}$ In this review, we will focus on the present status of AIH in the Asia-Pacific area.

\section{Epidemiology, natural history and genetics of AIH}

In the Asia-Pacific area, AIH incidence ranges from 0.67 (southern Israel) to 2.0 (Canterbury, New Zealand) per 100000 people, and its prevalence ranges from 4.0 (Singapore) to 24.5 (Canterbury, New Zealand) per 100000 people (Table 1). ${ }^{11-16}$ Survival rates reported from these studies are listed in Table 1 . The development of hepatocellular carcinoma (HCC) is strictly associated with long-standing cirrhotic AIH patients. ${ }^{17}$ Several studies from Japan, China, Iran, Israel and New Zealand have shown that the long-term survival in $\mathrm{AIH}$ is satisfactory and have identified the occurrence rate of $\mathrm{HCC}$ in $\mathrm{AIH}$ population as ranging from $3.3 \%$ to $5.1 \%$ (Tables 1 and 2). ${ }^{18-23}$

In 2012, the Japanese National Hospital Organization observed a large AIH cohort, which showed the 15-year survival rate to be $89.3 \%$ and $3.6 \%$ (7/193) of patients who developed HCC during follow-up. Cirrhosis was a particular risk factor for HCC (hazard ratio: 11.47, $p=0.005$ ). Male sex was also related to the risk for HCC in this population $(p=0.033) .{ }^{18}$ Similarly, Hino-Arinaga et al. ${ }^{19}$ revealed that cirrhosis at diagnosis (odds ratio: $4.08, p=0.0138$ ) and abnormal alanine aminotransferase (ALT) (odds ratio: 3.66, $p=0.0236$ ) at final follow-up were related to HCC. Cirrhotic patients are recommended to be closely monitored by abdominal ultrasonography as well as by detection of serum tumor markers for HCC.

AIH is a polygenic disease, and human leukocyte antigens (HLAs) are the most important genetic risk factors correlated to AIH. The genetic susceptibility maps to the DRB1 region on chromosome 6p21.3. Among European and North American patients with type I AIH, the dominant susceptible genes are HLA-DR3 (DRB1*0301) and -DR4 (DRB1*0401). ${ }^{17}$ HLA-DR3 patients have a higher risk for liver exhaustion and are younger than HLA-DR4 patients. ${ }^{24}$ HLA-DR4 (DRB1*0405) is more common in Chinese and Japanese case series, with the frequency ranging from $35.1 \%$ to $71.6 \% .^{22,25-29}$ It is related to concurrent immune diseases, treatment response and a beneficial outcome. ${ }^{30,31}$

HLA-DR14 was also related to excellent biochemical response in a Japanese population. ${ }^{27}$ However, Furumoto et $a^{2}{ }^{28}$ thoroughly examined the implications of HLA-DR4 and did not find that the treatment efficacy depended on HLA-DR antigens in Japanese AIH patients. A study from Taiwan showed that the frequency of DR4 in AIH patients was only $36 \% .^{32}$ In Thailand, HLA-DRB1*0301 (odds ratio: 
Wang Q. et al: AIH in the Asia-Pacific area

Table 1. Epidemiology of autoimmune hepatitis in the Asia-Pacific area

\begin{tabular}{|c|c|c|c|c|c|}
\hline Author & Country or region & Period & Prevalence/100 000 & Incidence/100 000 & $\begin{array}{l}\text { Survival rate } \\
\text { or mortality }\end{array}$ \\
\hline Lee et al. ${ }^{11}$ & Singapore & 1990-1996 & $\begin{array}{l}4 \text { ( } 8 \text { in Malays; } 3 \text { in } \\
\text { Chinese; } 7 \text { in Indian) }\end{array}$ & NM & $\begin{array}{l}\text { 5-year survival } \\
\text { rate: } 71 \%\end{array}$ \\
\hline Jalihal et al. ${ }^{12}$ & Brunei Darussalam & $2006-2008$ & $\begin{array}{l}5.61 \text { (4.64 in Malays; } \\
12.97 \text { in Chinese; } \\
6.03 \text { in indigenous } \\
\text { peoples) }\end{array}$ & NM & $\begin{array}{l}\text { Mortality: } 15.8 \% \text {; } \\
\text { Progressive liver } \\
\text { failure: } 10.5 \%\end{array}$ \\
\hline Haider et al. ${ }^{13}$ & Canberra, Australia & NM & 8.0 & NM & Mortality: $2.4 \%$ \\
\hline Ngu et al. ${ }^{14}$ & $\begin{array}{l}\text { Canterbury, } \\
\text { New Zealand }\end{array}$ & $2001-2008$ & $\begin{array}{l}24.5 \text { ( } 35.3 \text { in females; } \\
13.2 \text { in males); ( } 28.3 \\
\text { in Caucasian; } 5.1 \text { in } \\
\text { Maori; } 10.1 \text { in Pacific } \\
\text { Islander; } 6.8 \text { in Asian) }\end{array}$ & 2.0 & NM \\
\hline Delgado et al. ${ }^{15}$ & South Israel & 1995-2010 & $\begin{array}{l}11.0 \text { (19.5 in females; } \\
0.68 \text { in males) }\end{array}$ & $\begin{array}{l}0.67 \text { ( } 1.3 \\
\text { in females; } \\
0.26 \text { in males) }\end{array}$ & $\begin{array}{l}1 \text {-year survival } \\
\text { rate: } 96.5 \% \\
10 \text {-year survival } \\
\text { rate: } 89.7 \%\end{array}$ \\
\hline Kim et al. ${ }^{16}$ & South Korea & $2009-2013$ & $\begin{array}{l}4.82 \text { ( } 8.35 \text { in females; } \\
1.30 \text { in males) }\end{array}$ & $\begin{array}{l}1.07 \text { ( } 1.83 \\
\text { in females; } \\
0.31 \text { in males })\end{array}$ & NM \\
\hline
\end{tabular}

Abbreviation: NM, not mentioned.

3.92, $p=0.021$ ) and HLA-DQA $1 * 0101$ (odds ratio: $2.31, p=$ 0.019 ) were significantly associated with AIH when compared to controls. ${ }^{33}$

HLA-DRB1*1501 (40\%), HLA-DRB1*14 (30\%), HLADRB $1 * 0301 \quad(20 \%)$ and HLA-DRB $1 * 1301(15 \%)$ were increased in type I AIH patients from western India. ${ }^{34}$ Recently, another study indicated that HLA-DRB1*04 (odds ratio: $3.292, p=0.008$ ) and $\mathrm{DRB} 1 * 08$ (odds ratio: 10.5 , $p=0.027$ ) were significantly associated with type I AIH in the north Indian population. In the same cohort, patients with type II AIH were found to be significantly associated with DRB1*14 (odds ratio: $3.5, p=0.047$ )..$^{35}$

Hassan et al. ${ }^{36}$ reported a genetic association of HLA DR6, along with its subtypes HLA-DRB1*14 and HLA-DRB1*13, in Pakistan patients with $\mathrm{AIH}$. Moreover, $84.4 \%$ of the patients in that study presented with cirrhosis, and a single patient developed HCC.

\section{Characteristics of AIH}

AIH has different clinical phenotypes and changeable presentations. ${ }^{37}$ The spectrum of initial manifestations ranges from asymptomatic or mild nonspecific symptoms to acute hepatic failure. ${ }^{38,39}$ Some patients may not present until the stage of decompensated cirrhosis. In general, the elevated concentrations of serum ALT, aspartate aminotransferase (AST) and immunoglobulin G (IgG)/gamma-globulin, and presence of autoantibodies are meaningful laboratory features. ${ }^{40}$ In addition, the interpretation of ALT, AST and IgG within the normal levels could predict the risk of relapse. ${ }^{41}$

A typical histological characteristic of AIH is moderate or severe interface hepatitis (at the portal-parenchymal interface). ${ }^{42,43}$ Lymphocytes/plasma cells infiltrating portal and periportal areas, hepatocellular rosette formation and emperipolesis are also typical hallmarks of AIH. A recent study from our group showed that emperipolesis in AIH is related to higher levels of ALT/AST and more severe histological changes of necroinflammation. ${ }^{44}$

\section{Diagnostic criteria of AIH}

AIH diagnosis is based on detection of clinical and biochemical features, including increased serum IgG/gamma-globulin levels, presence of autoantibodies, and typical or compatible histology. Exclusion of other diseases (e.g., non-alcoholic steatohepatitis (NASH), alcoholic liver disease, chronic viral hepatitis, drug-induced liver injury, and Wilson's disease) is also important for diagnosing. ${ }^{17}$ The overall diagnostic accuracy of the revised IAIHG criteria $(1999)^{3}$ was $89.8 \%$, but it is difficult to use in routine clinical investigation. The simplified IAIHG diagnostic criteria $(2008)^{4}$ has been proved as relatively reliable in classical subgroups of AIH patients, but is less reliable in atypical and pediatric-age patients. ${ }^{5-9,45}$

Miyake et al. ${ }^{5}$ reported that the simplified criteria had lower sensitivity ( $85 \%$ vs. $100 \%$ ) and higher specificity ( $99 \%$ vs. $93 \%$ ) than the revised criteria following their study of 176 Japanese patients with $\mathrm{AIH}$. In this cohort, $23 \%$ of cases showing acute presentation and $50 \%$ of cases with histological acute hepatitis were not diagnosed as AIH using the simplified criteria. Later, another study from Japan evaluated the diagnostic value of this new criteria in acute-onset AIH (29 non-severe type, 14 severe type and 12 fulminant type). Among the 55 total patients, 33 (60\%) were diagnosed as "non-diagnostic" based on the simplified scoring system. Whereas, the revised criteria performed better in this atypical subgroup, with only 5 ( $9 \%$ ) of acute-onset cases being missed by the AIH diagnosis. ${ }^{46}$

One validating study from Korea showed the sensitivity and positive predictive values of the simplified criteria were $69.9 \%$ and $86.4 \%$ respectively for the diagnosis of "probable $\mathrm{AIH}^{\prime 4}$. In 2011, our group validated these two IAIHG diagnostic 


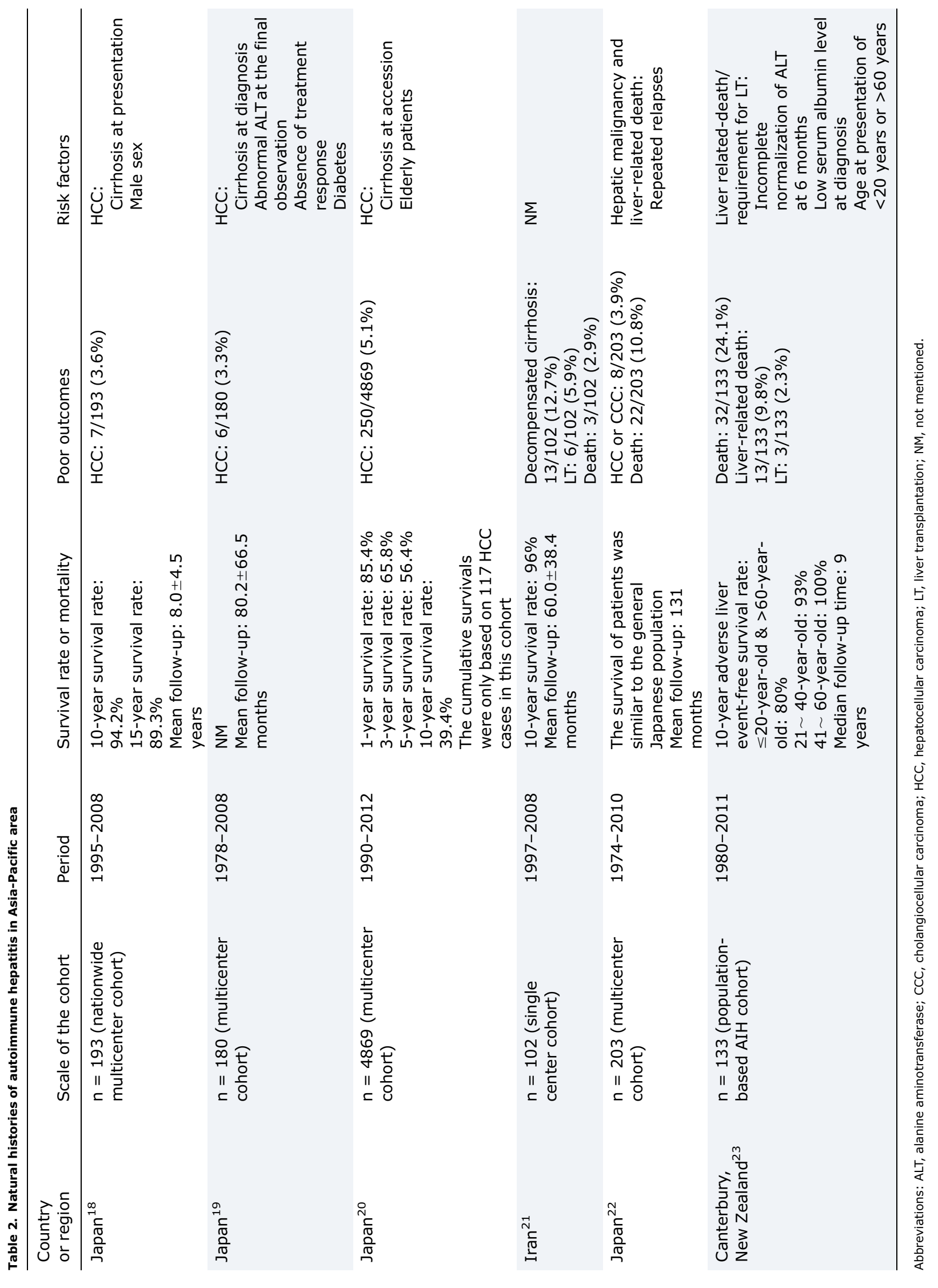


scoring criteria in 127 type I AIH patients. The specificity and sensitivity of simplified criteria was $95 \%$ and $90 \%$, respectively. Patients with negative autoantibodies, alkaline phosphatase/AST ratios of less than 1.5, and normal IgG concentrations but high gamma-globulin levels were more likely to miss the diagnosis of AIH according to the simplified criteria. In these patients, the revised criteria, along with histological examination, could help to conclude a correct diagnosis opportunely. ${ }^{6}$

It is reported that the majority of AIH cases are detected at advanced stages and have higher mortality rates in South Asia compared to those in East Asia. ${ }^{48}$ Our group has shown that transient elastography can dependably evaluate liver fibrosis in AIH via liver stiffness measurement $(r=0.752, p<$ 0.01). ${ }^{49}$ Transient elastography can be routinely used during AIH patient follow-up because of its noninvasive advantage. Since biochemical and histological features are nonspecific, it is essential to find some new and highly specific markers for accurate diagnosis of $\mathrm{AIH}$.

\section{Treatment of AIH}

The targets of treatment in AIH are to lessen liver inflammation and fibrosis, and obtain complete biochemical and histological remission. Predniso(lo)ne monotherapy and predniso(lo)ne/azathioprine combination regimen are two widely used treatments to induce remission in $\mathrm{AIH} .{ }^{50-52} \mathrm{~A}$ clinical study of AIH from India showed that timely initiation of immunosuppressive therapy was associated with a favorable prognosis. ${ }^{53}$ Our group evaluated the immunosuppressive treatment response of 115 consecutive Chinese AIH patients and found the complete biochemical remission rate was $87 \%$ within 36 months. ${ }^{54}$

Azathioprine is the prodrug of 6-mercaptopurine (6-MP). The most common side effect is cytopenia. Recently, a study from two large European liver centers showed that 75\% (15/ 20) of AIH cases with prior azathioprine intolerance responded to 6-MP therapy. Moreover, 6-MP was well tolerated in these 15 patients. ${ }^{55}$ Budesonide is only recommended for non-cirrhotic AIH cases, ${ }^{56}$ because cirrhosis patients have an increased risk of portal vein thrombosis. ${ }^{52}$ Intravenous glycyrrhizin has been used in treating liver diseases for more than 30 years in the Asian countries, mainly in Japan. Fujiwara and colleagues ${ }^{57}$ prospectively evaluated the effect of intravenous glycyrrhizin in acute-onset $\mathrm{AIH}$, and found that timely glycyrrhizin with sufficient doses $(100 \mathrm{~mL} /$ day) might improve ALT and avoid the progression to severe and fulminant stage.

There are several studies or experiences reported for mycophenolate mofetil, cyclosporin, tacrolimus and infliximab, in their role as rescue drugs in intolerant and/or refractory $\mathrm{AIH}$ cases. ${ }^{58-65}$ Although these second-line immunosuppressive therapies have been used with variable success, further multicenter randomized control prospective trials should be undertaken. ${ }^{66}$ However, novel immunotherapies, such as expanding functional autologous $T$ regulatory cells ${ }^{67,68}$ and myeloidderived suppressor cells ${ }^{69}$ are promising but need further investigations to confirm the related safety and effectiveness.

Relapses of $\mathrm{AIH}$ are frequent after drug withdrawal. Takahashi et al. ${ }^{70}$ found that, compared with sustained remission patients, the rate of glucocorticoid reduction until serum ALT normalization (mg/week) was significantly increased in relapsed patients ( 1.37 vs. $2.60, p=0.038$ ). Immunosuppressive therapy is recommended to continue for at least 3 years. ${ }^{17}$ Early administration of azathioprine after the first relapse was effective to combat extra recrudescence. ${ }^{71}$
Liver transplantation is an effective treatment for decompensated liver diseases. Liver transplantation should be considered in AIH cases that have progressed to end-stage liver disease or acute liver failure. The long-term survival is relatively optimistic in AIH patients who received liver transplantation, and the $5 \sim 10$-year survival rates are about $75 \% .{ }^{17,72}$

\section{Special subgroups of AIH}

\section{Presentations}

\section{Acute/acute severe $\mathrm{AIH}$}

AIH generally has a chronic presentation with serum ALT and/ or aspartate aminotransferase abnormalities, whereas it can also present as an acute/acute severe disease. ${ }^{73} \mathrm{~A}$ Japanese nationwide survey found that about $10 \%$ of AIH cases showed acute hepatitis in histological examinations. ${ }^{74}$ Zone 3 necrosis is a histological feature of acute AIH. ${ }^{75}$ Centrilobular necrosis was observed in $31.7 \%$ (13/41) of acute and acute exacerbation phase cases in Japanese type I AIH. ${ }^{76}$

When AIH presents acute/acute severe onset, patients may not have high IgG concentrations and serum autoantibodies to fulfill the IAIHG diagnosis criteria, especially using the simplified criteria. ${ }^{75,77,78}$ Furthermore, histological features may also be atypical, and these AIH patients are likely to be misdiagnosed as cryptogenic hepatitis. Several studies have shown that intravenous glycyrrhizin was not only safe but also effective for acute liver diseases, ${ }^{57,79,80}$ suggesting it can be used as an initial treatment before starting the disease-specific therapy for the patients with 'cryptogenic' hepatitis. Intravenous prednisolone treatment (up to 100 $\mathrm{mg} /$ day) is recommended in acute/acute severe AIH. ${ }^{52}$

Zhu et al. ${ }^{81}$ retrospectively analyzed 22 Chinese $\mathrm{AIH}-$ induced liver failure cases and found four survivors (18.2\%) who showed younger age and shorter duration from diagnosis to glucocorticoids administration in contrast to the nonsurvivors. Since many acute AIH patients with higher levels of bilirubin (more than $10 \mathrm{mg} / \mathrm{dL}$ ) and titers of anti-nuclear antibody (ANA) ( $\geq 1: 160)$ respond poorly to glucocorticoid therapy, ${ }^{82}$ sufferers who do not benefit from 2-week glucocorticoid treatment should be deliberated for liver transplantation. ${ }^{83}$

\section{Cirrhosis}

About $25 \%$ of $\mathrm{AIH}$ patients are cirrhotic at presentation. ${ }^{50}$ Miyake et al. ${ }^{84}$ established a model [risk score $=-0.113+$ $0.0006056 \times \operatorname{IgA}(\mathrm{mg} / \mathrm{dL})+0.155 \times$ ratio of aspartate aminotransferase to ALT $-0.007079 \times$ platelet $\left(\times 10^{4} / \mathrm{mm}^{3}\right)$ ] for determining cirrhosis in type I AIH patients. Risk score $\geq 0.20$ was estimated to be cirrhotic, with specificity and sensitivity of $83 \%$ and $90 \%$, respectively. From 1975 to 2010, Abe et al. ${ }^{85}$ found that $20.4 \%$ of patients with type I AIH $(n=250)$ were cirrhotic in a Japanese population. During the follow-up period, the relapse rate was high in patients who developed cirrhosis. Therefore, lifespan maintenance therapy is encouraged in this population. ${ }^{86}$

Cirrhosis is related to a higher proportion ( $25 \%$ vs. $8 \%$ ) of drug-related complications ${ }^{87,88}$ and fragmentary response to therapy. In the corticosteroid part of the regimen, predniso (lo)ne is appropriate for AIH patients at the advanced cirrhosis stage. With respect to the immunosuppressive regimen, the main side effect of azathioprine or 6-MP is cytopenia, which can be frequent in cirrhosis and cirrhosis-related 
hypersplenism. ${ }^{89,90}$ Therefore, azathioprine and 6-MP should be avoided in patients with white blood cell count $<2.5 \times 10^{9} / \mathrm{L}$ or platelet counts $<50 \times 10^{9} / \mathrm{L}$, or with complete thiopurine methyltransferase deficiency. ${ }^{50}$ Complete blood count must be closely monitored (2- to 4-week intervals) during therapy.

For those in the decompensated stage, the treatmentrelated side effects could otherwise be amplified. Recently, our group retrospectively analyzed the outcomes of $82 \mathrm{AIH}$ patients in the decompensated cirrhosis state. In the corticosteroid-treated group, $62.5 \%(40 / 64)$ patients reverted to the compensated state. ${ }^{91}$ The benefits of immunosuppressants should be compared to the higher risk of gastrointestinal bleeding and infection, and adjunctive therapies like antacids and sympatholytic nonselective beta-blockers are recommended.

HCC development in AIH does exist and is associated with cirrhosis, although it is less common than other causes of liver diseases. ${ }^{92}$ For the cirrhosis subgroup, routine imaging examinations, like those by ultrasound, should be done at 6-month intervals to exclude HCC. ${ }^{93}$

\section{Autoantibodies}

The common diagnostic markers of type I AIH are ANA and/or anti-smooth muscle antibodies (ASMA). Type I AIH affects both children and adults. Anti-liver kidney microsome-1 and/ or anti-liver cytosol-1 (LC-1) characterize type II AIH. Type II AIH usually occurs in children and/or adolescents. ${ }^{94}$

\section{Autoantibody-negative AIH}

Some serum autoantibody-negative patients with typical AIH histological characteristics are diagnosed with cryptogenic hepatitis. ${ }^{95}$ In 2009, a retrospective analysis from Miyake and colleagues $^{96}$ showed that $13.6 \%(24 / 176)$ of patients with type I AIH were negative for ANA. Although ANA-negative cases had acute-onset more frequently, the corticosteroid response was not different between ANA-positive cases and ANA-negative cases. ${ }^{96}$

Serum antibody-negative $\mathrm{AIH}$ is not rare in the Chinese population. Our center has found $10.2 \%$ (17/167) of AIH cases with absence of ANA and ASMA at presentation, with 4 patients becoming autoantibody-positive (ANA) during the follow-up period. ${ }^{97}$ Compared with classical $\mathrm{AIH}$, the antibody-negative group had lower IgG concentrations. The IAIHG criteria (1999) are confident for evaluating antibodynegative AIH. Moreover, the complete biochemical remission rates have shown no significant differences within 24 months between classical and autoantibody-negative AIH cases. In our routine practice, physicians should attach importance to this phenotype of $\mathrm{AIH}$, making early diagnosis and starting corticosteroid treatment promptly to improve prognosis.

\section{Anti-soluble liver antigen/liver pancreas antigen (anti-SLA/ $L P$ )-positive $A I H$}

Anti-SLA/LP is useful to identify AIH cases without classical serum autoantibodies. It is related to severe disease course and relapse. ${ }^{31}$ Zhao et al. ${ }^{98}$ reported that SLA-specific interferon- $\gamma$ responses were more continual in their AIH group of patients $(58.1 \%)$ than those in their control groups (primary biliary cholangitis (PBC): $6.7 \%$, hepatitis $\mathrm{B} / \mathrm{C}$ : $4.3 \%$, healthy subjects: $0 \%$ ). Whether anti-SLA/LP characterizes type III AIH remains controversial. ${ }^{52}$

\section{Antimitochondrial antibodies-positive AIH}

Antimitochondrial antibodies, assay markers of PBC, may occur in AIH without any other evidence of PBC. ${ }^{17}$ Anticentromere antibodies (ACA) are commonly observed in $\mathrm{PBC}^{99}$ while occasionally detected in AIH. Himoto et al. ${ }^{100}$ studied the clinical characteristics of ACA-seropositive AIH cases in their cohort and found that $17 \%(8 / 47)$ of the patients had ACA. Compared with the classical AIH group, the ACA-positive group had lower serum IgG concentrations and higher proportion of concurrent autoimmune diseases. ${ }^{100}$ About $50 \%$ of AIH patients have a clinical history of jaundice. ${ }^{101}$ Second-line immunosuppressive treatment (i.e. mycophenolate mofetil or tacrolimus) should be premeditated in icteric AIH patients who fail standard therapy. ${ }^{62,102,103}$

\section{AIH patients with characteristics of PBC}

Characteristics of PBC may occur in AIH, most habitually as AIH-PBC overlap syndromes. ${ }^{104}$ The Paris criteria (1998) include three AIH criteria and three PBC criteria. ${ }^{105}$ Since serum ASMA positivity are less common and IgG concentrations are rare above $2 \times$ the upper limit of normal (ULN) in the Asia-Pacific area, ${ }^{10}$ the diagnostic value of these AIH-PBC overlap syndrome criteria is probably not satisfactory. A study from China ${ }^{106}$ reported that the sensitivity rate of serum IgG concentration $\geq 1.3 \times U L N$ was $60 \%$, while that of Paris criteria was only $10 \%$.

Recently, our group analyzed the clinical data of 323 patients with PBC, 46 (14.2\%) of them with features of AIH. The 5 -year survival rate of these 46 cases was $58 \%$, which was less than $81 \%$ in other PBC cases without AIH features. ${ }^{107}$ Corticosteroids added to ursodeoxycholic acid is useful to increase the response rates in AIH-PBC overlap syndrome patients. ${ }^{108} \mathrm{~A}$ nationwide study from Japan showed that the simplified AIH scoring system was beneficial for selection of patients who require corticosteroids administration ${ }^{109}$ (Fig. 1).

\section{AIH patients within the context of NASH}

Like in western countries, with the increased frequency of overweight and obesity during the past two decades, NASH has become an emerging problem in the Asia-Pacific area. It has been noted that low titers of ANA and ASMA are present in up to one-third of NASH patients. ${ }^{110,111}$ Meanwhile, some NASH patients also present mild hypergammaglobulinaemia. The similarities in autoantibody and elevated IgG levels lead to diagnostic confusion. Under such circumstances, histological examination is critical. ${ }^{45}$

Due to the side effects of corticosteroids (e.g., obesity, hypertension and diabetes), using the lowest dose of corticosteroids combined with dietary and exercise approach should be recommended in this population. ${ }^{17}$ One case report from Japan described a patient with NASH-AIH overlap who successfully achieved histological remission with a combination of prednisolone therapy and weight loss ${ }^{112}$ (Fig. 1).

\section{AIH patients within the context of chronic hepatitis B}

Chronic hepatitis B is considered the dominant reason of HCC in Asia-Pacific regions. Sui et al. ${ }^{113}$ have reported that the hepatitis B surface antigen (HBsAg)-positivity rate of Chinese $\mathrm{AIH}$ patients is $0.83 \%$, but sufferers with AIH still have high risk of hepatitis $B$ virus (HBV) infection and/or reactivation due 


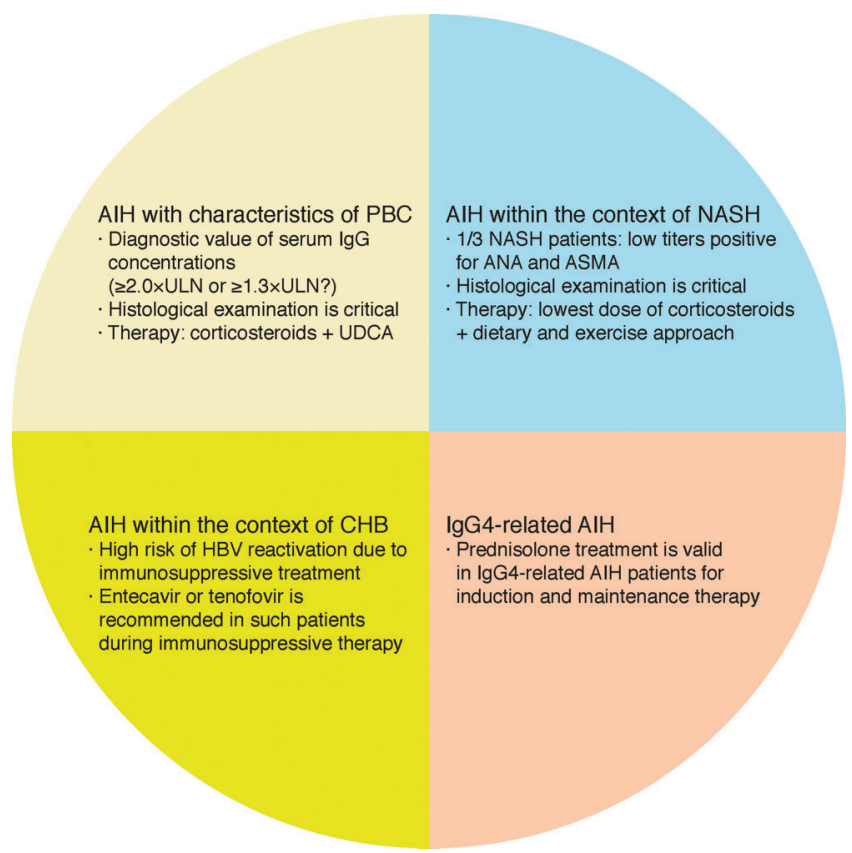

Fig. 1. Individualized treatment strategies of some special AIH subgroups.

to immunosuppressive treatment. By now, there is a worldwide consensus (at least among hepatologists) that HBsAgpositive patients should be protected against HBV reactivation when receiving immunosuppressive therapy. ${ }^{114}$

At present, the most reliable test used in clinical practice to diagnose HBV reactivation is the demonstration of a rise of one log in serum HBV DNA levels. Entecavir or tenofovir is recommended for such patients during immunosuppressive therapy and for 12 months after cessation of therapy. ${ }^{17}$ It is worth mentioning that the identification of anti-hepatitis $B$ core positivity in the absence of $\mathrm{HBsAg}$ in candidate $\mathrm{AIH}$ patients for immunosuppressive therapy requires further investigation due to the risk of HBV reactivation ${ }^{115}$ (Fig. 1).

\section{IgG4-related AIH}

IgG4-related $\mathrm{AIH}$, which was first reported in $2007,{ }^{116}$ shows more severe inflammatory activity compared with classical AIH. However, it is hard to determine whether a substance of AIH-like IgG4 disease exists or expresses a separate disease entity. ${ }^{17}$ Umemura et al. ${ }^{117}$ defined IgG4-related AIH as the infiltration of IgG4-positive plasma cells ( $>10$ cells per high power field) and serum IgG4 level $\geq 135 \mathrm{mg} / \mathrm{dL}$, and found only $3.3 \%(2 / 60)$ cases fulfill the criteria in Japanese patients with type I AIH. Prednisolone treatment is valid in IgG4-related $\mathrm{AIH}$ patients for induction and maintenance therapy. ${ }^{118} \mathrm{~A}$ case report from China described a patient who developed IgG4 de novo AIH after ribavirin + pegylated-interferon alpha-2a treatment ${ }^{119}$ (Fig. 1).

\section{Conclusions and perspectives}

The typical phenotype of AIH is well recognized, but the special subgroups like autoantibody seronegative $\mathrm{AIH}$, acute severe $\mathrm{AIH}$, presenting with concomitant features of PBC, and within the context of other liver diseases, make the diagnosis and therapy challengeable. At present, the main misunderstandings are as follows: (1) Diagnosis is made only by serum autoantibodies, ignoring the diagnostic value of serum IgG; (2) Clinical and pathological diagnosis cannot be well combined to guide the treatment; (3) The indications for immunosuppressive therapy are not properly applied in clinical practice; (4) Insufficient immunosuppressive therapy $(<3$ years) or poor patient compliance; (5) Biochemical remission is not equivalent to histological remission.

Special phenotypes of AIH should be diagnosed and treated with flexible criteria and tailored management. Prompt immunosuppressive treatment is critical. For fulminant patients and those who have progressed to end-stage liver disease, liver transplantation could be conducted and the prognosis turns toward being quite optimistic. Nonetheless, further original studies that focus on the clinic and pathology of AIH in the Asia-Pacific area are needed.

\section{Acknowledgments}

This work was supported by grants from the National Natural Science Foundation of China (No. 81325002 and No. 81620108002 to X Ma, No. 81570511 and No. 81770564 to QX Wang), the Foundation for Innovative Research Groups of the National Natural Science Foundation of China (No. 81421001), and the Municipal Human Resources Development Program for Outstanding Young Talents in Medical and Health Sciences in Shanghai (No. 2017 Y037 to QX Wang).

\section{Conflict of interest}

The authors have no conflict of interests related to this publication.

\section{Author contributions}

Wrote the review (QXW, LY), edited the review (XM).

\section{References}

[1] Mackay IR. Historical reflections on autoimmune hepatitis. World J Gastroenterol 2008;14:3292-3300. doi: 10.3748/wjg.14.3292.

[2] Johnson PJ, McFarlane IG. Meeting report: International Autoimmune Hepatitis Group. Hepatology 1993;18:998-1005. doi: 10.1002/hep.1840180435.

[3] Alvarez F, Berg PA, Bianchi FB, Bianchi L, Burroughs AK, Cancado EL, et al. International Autoimmune Hepatitis Group Report: review of criteria for diagnosis of autoimmune hepatitis. J Hepatol 1999;31:929-938. doi: 10. 1016/S0168-8278(99)80297-9.

[4] Hennes EM, Zeniya M, Czaja AJ, Parés A, Dalekos GN, Krawitt EL, et al. Simplified criteria for the diagnosis of autoimmune hepatitis. Hepatology 2008;48:169-176. doi: 10.1002/hep.22322.

[5] Miyake Y, Iwasaki Y, Kobashi H, Yasunaka T, Ikeda F, Takaki A, et al. Clinical features of autoimmune hepatitis diagnosed based on simplified criteria of the International Autoimmune Hepatitis Group. Dig Liver Dis 2010;42:210215. doi: 10.1016/j.dld.2009.06.013.

[6] Qiu D, Wang Q, Wang $H$, Xie Q, Zang G, Jiang $H$, et al. Validation of the simplified criteria for diagnosis of autoimmune hepatitis in Chinese patients. J Hepatol 2011;54:340-347. doi: 10.1016/j.jhep.2010.06.032.

[7] Muratori P, Granito A, Pappas G, Muratori L. Validation of simplified diagnostic criteria for autoimmune hepatitis in Italian patients. Hepatology 2009; 49:1782-1783; author reply 1783. doi: 10.1002/hep.22825.

[8] Yeoman AD, Westbrook RH, Al-Chalabi T, Carey I, Heaton ND, Portmann BC, et al. Diagnostic value and utility of the simplified International Autoimmune Hepatitis Group (IAIHG) criteria in acute and chronic liver disease. Hepatology 2009;50:538-545. doi: 10.1002/hep.23042. 
[9] Czaja AJ. Performance parameters of the diagnostic scoring systems for autoimmune hepatitis. Hepatology 2008;48:1540-1548. doi: 10.1002/hep. 22513.

[10] Yang F, Wang Q, Bian Z, Ren LL, Jia J, Ma X. Autoimmune hepatitis: East meets west. J Gastroenterol Hepatol 2015;30:1230-1236. doi: 10. $1111 /$ jgh. 12952.

[11] Lee YM, Teo EK, Ng TM, Khor C, Fock KM. Autoimmune hepatitis in Singapore: a rare syndrome affecting middle-aged women. J Gastroenterol Hepatol 2001;16:1384-1389. doi: 10.1046/j.1440-1746.2001.02646.x.

[12] Jalihal A, Telisinghe PU, Chong VH. Profiles of autoimmune hepatitis in Brunei Darussalam. Hepatobiliary Pancreat Dis Int 2009;8:602-607.

[13] Haider AS, Kaye G, Thomson A. Autoimmune hepatitis in a demographically isolated area of Australia. Intern Med J 2010;40:281-285. doi: 10.1111/j. 1445-5994.2009.02041.x.

[14] Ngu JH, Bechly K, Chapman BA, Burt MJ, Barclay ML, Gearry RB, et al. Population-based epidemiology study of autoimmune hepatitis: a disease of older women? J Gastroenterol Hepatol 2010;25:1681-1686. doi: 10. 1111/j.1440-1746.2010.06384.x.

[15] Delgado JS, Vodonos A, Malnick S, Kriger O, Wilkof-Segev R, Delgado B, et al. Autoimmune hepatitis in southern Israel: a 15 -year multicenter study. J Dig Dis 2013;14:611-618. doi: 10.1111/1751-2980.12085.

[16] Kim BH, Choi HY, Ki M, Kim KA, Jang ES, Jeong SH. Population-based prevalence, incidence, and disease burden of autoimmune hepatitis in South Korea. PLoS One 2017;12:e0182391. doi: 10.1371/journal.pone.0182391.

[17] European Association for the Study of the Liver. EASL Clinical Practice Guidelines: Autoimmune hepatitis. J Hepatol 2015;63:971-1004. doi: 10. 1016/j.jhep.2015.06.030

[18] Migita K, Watanabe $Y$, Jiuchi $Y$, Nakamura $Y$, Saito A, Yagura M, et al. Hepatocellular carcinoma and survival in patients with autoimmune hepatitis (Japanese National Hospital Organization-autoimmune hepatitis prospective study). Liver Int 2012;32:837-844. doi: 10.1111/j.1478-3231.2011. 02734.x.

[19] Hino-Arinaga T, Ide T, Kuromatsu R, Miyajima I, Ogata K, Kuwahara R, Hisamochi $A$, et al. Risk factors for hepatocellular carcinoma in Japanese patients with autoimmune hepatitis type 1. J Gastroenterol 2012;47:569576. doi: 10.1007/s00535-011-0519-2.

[20] Ohira H, Abe K, Takahashi A, Zeniya M, Ichida T. Clinical features of hepatocellular carcinoma in patients with autoimmune hepatitis in Japan. J Gastroenterol 2013;48:109-114. doi: 10.1007/s00535-012-0616-x.

[21] Malekzadeh Z, Haghazali S, Sepanlou SG, Vahedi H, Merat S, Sotoudeh M, et al. Clinical features and long term outcome of 102 treated autoimmune hepatitis patients. Hepat Mon 2012;12:92-99. doi: 10.5812/hepatmon.808

[22] Yoshizawa K, Matsumoto A, Ichijo T, Umemura T, Joshita S, Komatsu M, et al. Long-term outcome of Japanese patients with type 1 autoimmune hepatitis. Hepatology 2012;56:668-676. doi: 10.1002/hep.25658

[23] Ngu JH, Gearry RB, Frampton CM, Stedman CA. Predictors of poor outcome in patients $w$ ith autoimmune hepatitis: a population-based study. Hepatology 2013;57:2399-2406. doi: 10.1002/hep.26290.

[24] Czaja AJ, Manns MP. Advances in the diagnosis, pathogenesis, and management of autoimmune hepatitis. Gastroenterology 2010;139:58-72.e4. doi: 10.1053/j.gastro.2010.04.053.

[25] Ma X, Qiu DK. Relationship between autoimmune hepatitis and HLA-DR4 and DRbeta allelic sequences in the third hypervariable region in Chinese. World J Gastroenterol 2001;7:718-721. doi: 10.3748/wjg.v7.i5.718.

[26] Koay LB, Lin CY, Tsai SL, Lee C, Lin CN, Sheu MJ, et al. Type 1 autoimmune hepatitis in Taiwan: diagnosis using the revised criteria of the International Autoimmune Hepatitis Group. Dig Dis Sci 2006;51:1978-1984. doi: 10. 1007/s10620-005-9068-y.

[27] Suzuki Y, Ikeda K, Hirakawa M, Kawamura $Y$, Yatsuji $H$, Sezaki $H$, et al. Association of HLA-DR14 with the treatment response in Japanese patients with autoimmune hepatitis. Dig Dis Sci 2010;55:2070-2076. doi: 10. 1007/s10620-009-0995-x.

[28] Furumoto $Y$, Asano T, Sugita T, Abe H, Chuganji Y, Fujiki K, et al. Evaluation of the role of HLA-DR antigens in Japanese type 1 autoimmune hepatitis. BMC Gastroenterol 2015;15:144. doi: 10.1186/s12876-015-0360-9.

[29] Huang HC, Wu JC, Huang YS, Teh-Ia H, Lo JC, Li CP, et al. Genetic distinctions and clinical characteristics of type 1 autoimmune hepatitis in Taiwan. Hepatogastroenterology 2008;55:605-608.

[30] Czaja AJ. Autoimmune hepatitis in special patient populations. Best Pract Res Clin Gastroenterol 2011;25:689-700. doi: 10.1016/j.bpg.2011.09.011.

[31] Kirstein MM, Metzler F, Geiger E, Heinrich E, Hallensleben M, Manns MP, et al. Prediction of short- and long-term outcome in patients with autoimmune hepatitis. Hepatology 2015;62:1524-1535. doi: 10.1002/hep. 27983.

[32] Koay LB, Sun CS, Tsai SL, Lin CY. Significant association of HLA-DQ5 with autoimmune hepatitis in Taiwan. J Formos Med Assoc 2007;106:10631068. doi: 10.1016/S0929-6646(08)60085-6.

[33] Tanwandee T, Wanichapol S, Vejbaesya S, Chainuvati S, Chotiyaputta W. Association between HLA class II alleles and autoimmune hepatitis type 1 in Thai patients. J Med Assoc Thai 2006;89 Suppl 5:S73-S78.
[34] Shankarkumar U, Amarapurkar DN, Kankonkar S. Human leukocyte antigen allele associations in type- 1 autoimmune hepatitis patients from western India. J Gastroenterol Hepatol 2005;20:193-197. doi: 10.1111/j.14401746.2004.03608.x.

[35] Kaur N, Minz RW, Anand S, Saikia B, Aggarwal R, Das A, et al. HLA DRB1 Alleles Discriminate the Manifestation of Autoimmune Hepatitis as Type 1 or Type 2 in North Indian Population. J Clin Exp Hepatol 2014;4:14-18. doi: 10.1016/j.jceh.2013.12.002.

[36] Hassan N, Siddiqui AR, Abbas Z, Hassan SM, Soomro GB, Mubarak M, et al. Clinical profile and HLA typing of autoimmune hepatitis from Pakistan. Hepat Mon 2013;13:e13598. doi: 10.5812/hepatmon.13598.

[37] Wang Q, Yang F, Miao Q, Krawitt EL, Gershwin ME, Ma X. The clinical phenotypes of autoimmune hepatitis: A comprehensive review. J Autoimmun 2016;66:98-107. doi: 10.1016/j.jaut.2015.10.006.

[38] Kogan J, Safadi R, Ashur Y, Shouval D, Ilan Y. Prognosis of symptomatic versus asymptomatic autoimmune hepatitis: a study of 68 patients. J Clin Gastroenterol 2002;35:75-81. doi: 10.1097/00004836-200207000-00016.

[39] Feld JJ, Dinh H, Arenovich T, Marcus VA, Wanless IR, Heathcote EJ. Autoimmune hepatitis: effect of symptoms and cirrhosis on natural history and outcome. Hepatology 2005;42:53-62. doi: 10.1002/hep.20732.

[40] Schramm C, Weiler-Normann C, Wiegard C, Hellweg S, Müller S, Lohse AW. Treatment response in patients with autoimmune hepatitis. Hepatology 2010;52:2247-2248. doi: 10.1002/hep.23840.

[41] Hartl J, Ehlken H, Weiler-Normann C, Sebode M, Kreuels B, Pannicke N, et al. Patient selection based on treatment duration and liver biochemistry increases success rates after treatment withdrawal in autoimmune hepatitis. J Hepatol 2015;62:642-646. doi: 10.1016/j.jhep.2014.10.018.

[42] Al-Chalabi T, Boccato S, Portmann BC, McFarlane IG, Heneghan MA. Autoimmune hepatitis (AIH) in the elderly: a systematic retrospective analysis of a large group of consecutive patients with definite AIH followed at a tertiary referral centre. J Hepatol 2006;45:575-583. doi: 10.1016/j.jhep. 2006.04.007.

[43] Czaja AJ, Carpenter HA. Sensitivity, specificity, and predictability of biopsy interpretations in chronic hepatitis. Gastroenterology 1993;105:18241832. doi: 10.1016/0016-5085(93)91081-R.

[44] Miao Q, Bian Z, Tang R, Zhang H, Wang Q, Huang S, et al. Emperipolesis mediated by CD8 T cells is a characteristic histopathologic feature of autoimmune hepatitis. Clin Rev Allergy Immunol 2015;48:226-235. doi: 10. 1007/s12016-014-8432-0.

[45] Wiegard C, Schramm C, Lohse AW. Scoring systems for the diagnosis of autoimmune hepatitis: past, present, and future. Semin Liver Dis 2009; 29:254-261. doi: 10.1055/s-0029-1233532.

[46] Fujiwara K, Yasui S, Tawada A, Fukuda Y, Nakano M, Yokosuka O. Diagnostic value and utility of the simplified International Autoimmune Hepatitis Group criteria in acute-onset autoimmune hepatitis. Liver Int 2011;31:10131020. doi: 10.1111/j.1478-3231.2011.02524.x.

[47] Kim BH, Kim YJ, Jeong SH, Tak WY, Ahn SH, Lee YJ, et al. Clinical features of autoimmune hepatitis and comparison of two diagnostic criteria in Korea: a nationwide, multicenter study. J Gastroenterol Hepatol 2013;28:128-134. doi: 10.1111/j.1440-1746.2012.07292.x.

[48] Tanaka A, Ma X, Yokosuka O, Weltman M, You H, Amarapurkar DN, et al. Autoimmune liver diseases in the Asia-Pacific region: Proceedings of APASL symposium on AIH and PBC 2016. Hepatol Int 2016;10:909-915. doi: 10. 1007/s12072-016-9767-9

[49] Xu Q, Sheng L, Bao H, Chen X, Guo C, Li H, et al. Evaluation of transient elastography in assessing liver fibrosis in patients with autoimmune hepatitis. J Gastroenterol Hepatol 2017;32:639-644. doi: 10.1111/jgh.13508.

[50] Manns MP, Czaja AJ, Gorham JD, Krawitt EL, Mieli-Vergani G, Vergani D, et al. Diagnosis and management of autoimmune hepatitis. Hepatology 2010; 51:2193-2213. doi: 10.1002/hep.23584.

[51] Gleeson D, Heneghan MA. British Society of Gastroenterology. British Society of Gastroenterology (BSG) guidelines for management of autoimmune hepatitis. Gut 2011;60:1611-1629. doi: 10.1136/gut.2010.235259.

[52] Manns MP, Lohse AW, Vergani D. Autoimmune hepatitis-Update 2015. J Hepatol 2015;62:S100-S111. doi: 10.1016/j.jhep.2015.03.005.

[53] Amarapurkar D, Dharod M, Amarapurkar A. Autoimmune hepatitis in India: single tertiary referral centre experience. Trop Gastroenterol 2015;36:3645. doi: $10.7869 / \mathrm{tg} .243$

[54] Wang Q, Qiu D, Ma X. Early normalisation of aminotransferase predicts complete biochemical remission in autoimmune hepatitis patients. Aliment Pharmacol Ther 2011;34:107-109. doi: 10.1111/j.1365-2036. 2011.04690.x.

[55] Hübener S, Oo YH, Than NN, Hübener $\mathrm{P}$, Weiler-Normann $\mathrm{C}$, Lohse AW, et al. Efficacy of 6-Mercaptopurine as Second-Line Treatment for Patients With Autoimmune Hepatitis and Azathioprine Intolerance. Clin Gastroenterol Hepatol 2016;14:445-453. doi: 10.1016/j.cgh.2015.09.037.

[56] Efe C, Ozaslan E, Kav T, Purnak T, Shorbagi A, Ozkayar O, et al. Liver fibrosis may reduce the efficacy of budesonide in the treatment of autoimmune hepatitis and overlap syndrome. Autoimmun Rev 2012;11:330-334. doi: 10.1016/j.autrev.2011.09.006 
[57] Yasui S, Fujiwara K, Tawada A, Fukuda Y, Nakano M, Yokosuka O. Efficacy of intravenous glycyrrhizin in the early stage of acute onset autoimmune hepatitis. Dig Dis Sci 2011;56:3638-3647. doi: 10.1007/s10620-011-1789-5.

[58] Sharzehi K, Huang MA, Schreibman IR, Brown KA. Mycophenolate mofeti for the treatment of autoimmune hepatitis in patients refractory or intolerant to conventional therapy. Can J Gastroenterol 2010;24:588-592. doi: $10.1155 / 2010 / 891252$

[59] Zachou K, Gatselis N, Papadamou G, Rigopoulou EI, Dalekos GN. Mycophenolate for the treatment of autoimmune hepatitis: prospective assessment of its efficacy and safety for induction and maintenance of remission in a large cohort of treatment-naïve patients. J Hepatol 2011;55:636-646. doi: 10.1016/j.jhep.2010.12.032.

[60] Sherman KE, Narkewicz M, Pinto PC. Cyclosporine in the management of corticosteroid-resistant type I autoimmune chronic active hepatitis J Hepatol 1994;21:1040-1047. doi: 10.1016/S0168-8278(05)80615-4.

[61] Fernandes NF, Redeker AG, Vierling JM, Villamil FG, Fong TL. Cyclosporine therapy in patients with steroid resistant autoimmune hepatitis. Am J Gastroenterol 1999;94:241-248. doi: 10.1111/j.1572-0241.1999.00807.x.

[62] Larsen FS, Vainer B, Eefsen M, Bjerring PN, Adel Hansen B. Low-dose tacrolimus ameliorates liver inflammation and fibrosis in steroid refractory autoimmune hepatitis. World J Gastroenterol 2007;13:3232-3236. doi: 10. 3748/wjg.v13.i23.3232.

[63] Tannous MM, Cheng J, Muniyappa K, Farooq I, Bharara A, Kappus M, et al. Use of tacrolimus in the treatment of autoimmune hepatitis: a single centre experience. Aliment Pharmacol Ther 2011;34:405-407. doi: 10.1111/j. 1365-2036.2011.04749.x.

[64] Weiler-Normann C, Schramm C, Quaas A, Wiegard C, Glaubke C, Pannicke $\mathrm{N}$, et al. Infliximab as a rescue treatment in difficult-to-treat autoimmune hepatitis. J Hepatol 2013;58:529-534. doi: 10.1016/j.jhep.2012.11.010.

[65] Than NN, Wiegard C, Weiler-Normann C, Füssel K, Mann J, Hodson J, et al. Long-term follow-up of patients with difficult to treat type 1 autoimmune hepatitis on Tacrolimus therapy. Scand J Gastroenterol 2016;51:329-336. doi: 10.3109/00365521.2015.1095351.

[66] Liberal R, de Boer YS, Andrade RJ, Bouma G, Dalekos GN, Floreani A, et al. Expert clinical management of autoimmune hepatitis in the real world. Aliment Pharmacol Ther 2017;45:723-732. doi: 10.1111/apt.13907.

[67] Longhi MS, Liberal R, Holder B, Robson SC, Ma Y, Mieli-Vergani G, et al. Inhibition of interleukin-17 promotes differentiation of $\mathrm{CD}^{2} 5^{-}$cells into stable T regulatory cells in patients with autoimmune hepatitis. Gastroenterology 2012;142:1526-1535.e6. doi: 10.1053/j.gastro.2012.02.041.

[68] Muratori L, Longhi MS. The interplay between regulatory and effector T cells in autoimmune hepatitis: Implications for innovative treatment strategies. J Autoimmun 2013;46:74-80. doi: 10.1016/j.jaut.2013.06.016.

[69] Zhang H, Liu Y, Bian Z, Huang S, Han X, You Z, et al. The critical role of myeloid-derived suppressor cells and FXR activation in immune-mediated liver injury. J Autoimmun 2014;53:55-66. doi: 10.1016/j.jaut.2014.02.010.

[70] Takahashi A, Ohira H, Abe K, Miyake Y, Abe M, Yamamoto K, et al. Rapid corticosteroid tapering: Important risk factor for type 1 autoimmune hepatitis relapse in Japan. Hepatol Res 2015;45:638-644. doi: 10.1111/hepr. 12397.

[71] Yokokawa J, Kanno Y, Saito H, Abe K, Takahashi A, Yokokawa H, et al. Risk factors associated with relapse of type 1 autoimmune hepatitis in Japan. Hepatol Res 2011;41:641-646. doi: 10.1111/j.1872-034X.2011.00812.x.

[72] Cho CW, Kwon CHD, Kim JM, Choi GS, Joh JW, Lee SK. Comparative analysis of the clinical outcomes of liver transplantation for probable and definite auto-immune hepatitis by international diagnostic scoring criteria. Transplant Proc 2017;49:1126-1128. doi: 10.1016/j.transproceed.2017.03.014.

[73] Yamamoto K, Miyake Y, Ohira H, Suzuki Y, Zeniya M, Onji M, et al. Prognosis of autoimmune hepatitis showing acute presentation. Hepatol Res 2013; 43:630-638. doi: 10.1111/j.1872-034X.2012.01109.x.

[74] Abe M, Mashiba T, Zeniya M, Yamamoto $K$, Onji M, Tsubouchi $H$, et al. Present status of autoimmune hepatitis in Japan: a nationwide survey. J Gastroenterol 2011;46:1136-1141. doi: 10.1007/s00535-011-0421-y.

[75] Miyake Y, Iwasaki Y, Kobashi H, Yasunaka T, Ikeda F, Takaki A, et al. Autoimmune hepatitis with acute presentation in Japan. Dig Liver Dis 2010;42: 51-54. doi: 10.1016/j.dld.2009.04.009.

[76] Abe K, Kanno Y, Okai K, Katsushima F, Monoe K, Saito H, et al. Centrilobular necrosis in acute presentation of Japanese patients with type 1 autoimmune hepatitis. World J Hepatol 2012;4:262-267. doi: 10.4254/wjh.v4.i9.262.

[77] Iwai M, Jo M, Ishii M, Mori T, Harada Y. Comparison of clinical features and liver histology in acute and chronic autoimmune hepatitis. Hepatol Res 2008;38:784-789. doi: 10.1111/j.1872-034X.2008.00347.x.

[78] Weiler-Normann C, Lohse AW. Acute autoimmune hepatitis: many open questions. J Hepatol 2014;61:727-729. doi: 10.1016/j.jhep.2014.06.030.

[79] Acharya SK, Dasarathy S, Tandon A, Joshi YK, Tandon BN. A preliminary open trial on interferon stimulator (SNMC) derived from Glycyrrhiza glabra in the treatment of subacute hepatic failure. Indian J Med Res 1993;98:69-74.

[80] Tandon A, Tandon BN, Bhujwala RA. Clinical spectrum of acute sporadic hepatitis $E$ and possible benefit of glycyrrhizin therapy. Hepatol Res 2002; 23:55-61. doi: 10.1016/S1386-6346(01)00155-3.
[81] Zhu B, You SL, Wan ZH, Liu HL, Rong YH, Zang H, et al. Clinical characteristics and corticosteroid therapy in patients with autoimmune-hepatitisinduced liver failure. World J Gastroenterol 2014;20:7473-7479. doi: 10. 3748/wjg.v20.i23.7473.

[82] Abe M, Onji M, Kawai-Ninomiya K, Michitaka K, Matsuura B, Hiasa Y, et al. Clinicopathologic features of the severe form of acute type 1 autoimmune hepatitis. Clin Gastroenterol Hepatol 2007;5:255-258. doi: 10.1016/j.cgh. 2006.10.011.

[83] Czaja AJ. Corticosteroids or not in severe acute or fulminant autoimmune hepatitis: therapeutic brinksmanship and the point beyond salvation. Liver Transpl 2007;13:953-955. doi: 10.1002/It.21088.

[84] Miyake $Y$, Iwasaki $Y$, Terada $R$, Nagano $T$, Kobashi $H$, Sakaguchi $K$, et al. A model for estimating cirrhosis in patients with type 1 autoimmune hepatitis. Hepatol Res 2008;38:658-663. doi: 10.1111/j.1872-034X.2008.00329.x.

[85] Abe K, Katsushima F, Kanno Y, Takahashi A, Yokokawa J, Ohira H, et al. Clinical features of cirrhosis in Japanese patients with type I autoimmune hepatitis. Intern Med 2012;51:3323-3328. doi: 10.2169/internalmedicine.51.8372.

[86] Krawitt EL. Autoimmune hepatitis. N Engl ] Med 2006;354:54-66. doi: 10. 1056/NEJMra050408.

[87] Summerskill WH, Korman MG, Ammon HV, Baggenstoss AH. Prednisone for chronic active liver disease: dose titration, standard dose, and combination with azathioprine compared. Gut 1975;16:876-883. doi: 10.1136/gut.16. 11.876.

[88] Uribe M, Go VL, Kluge D. Prednisone for chronic active hepatitis: pharmacokinetics and serum binding in patients with chronic active hepatitis and steroid major side effects. J Clin Gastroenterol 1984;6:331-335.

[89] Czaja AJ, Carpenter HA. Thiopurine methyltransferase deficiency and azathioprine intolerance in autoimmune hepatitis. Dig Dis Sci 2006;51:968975. doi: 10.1007/s10620-006-9336-5.

[90] Heneghan MA, Allan ML, Bornstein JD, Muir AJ, Tendler DA. Utility of thiopurine methyltransferase genotyping and phenotyping, and measurement of azathioprine metabolites in the management of patients with autoimmune hepatitis. J Hepatol 2006;45:584-591. doi: 10.1016/j.jhep.2006.05.011.

[91] Wang Z, Sheng L, Yang Y, Yang F, Xiao X, Hua J, et al. The management of autoimmune hepatitis patients with decompensated cirrhosis: real-world experience and a comprehensive review. Clin Rev Allergy Immunol 2017; 52:424-435. doi: 10.1007/s12016-016-8583-2.

[92] Zachou K, Muratori P, Koukoulis GK, Granito A, Gatselis N, Fabbri A, et al. Review article: autoimmune hepatitis - current management and challenges. Aliment Pharmacol Ther 2013;38:887-913. doi: 10.1111/apt.12470.

[93] Yeoman AD, Al-Chalabi T, Karani JB, Quaglia A, Devlin J, Mieli-Vergani G, et al. Evaluation of risk factors in the development of hepatocellular carcinoma in autoimmune hepatitis: Implications for follow-up and screening. Hepatology 2008;48:863-870. doi: 10.1002/hep.22432.

[94] Floreani A, Liberal R, Vergani D, Mieli-Vergani G. Autoimmune hepatitis: Contrasts and comparisons in children and adults - a comprehensive review. J Autoimmun 2013;46:7-16. doi: 10.1016/j.jaut.2013.08.004.

[95] Gassert DJ, Garcia H, Tanaka K, Reinus JF. Corticosteroid-responsive cryptogenic chronic hepatitis: evidence for seronegative autoimmune hepatitis. Dig Dis Sci 2007;52:2433-2437. doi: 10.1007/s10620-006-9665-4.

[96] Miyake Y, Iwasaki Y, Kobashi H, Yasunaka T, Ikeda F, Takaki A, et al. Clinical features of antinuclear antibodies-negative type 1 autoimmune hepatitis. Hepatol Res 2009;39:241-246. doi: 10.1111/j.1872-034X.2008.00454.x.

[97] Wang QX, Jiang WJ, Miao Q, Xiao X, Zhang HY, Huang SS, et al. Clinical and histological features of autoantibody-negative autoimmune hepatitis in Chinese patients: a single center experience. J Dig Dis 2013;14:175-180. doi: 10.1111/1751-2980.12022.

[98] Zhao Y, Zhang Y, Liu YM, Liu Y, Feng X, Liao HY, et al. Identification of T cell epitopes on soluble liver antigen in Chinese patients with auto-immune hepatitis. Liver Int 2011;31:721-729. doi: 10.1111/j.1478-3231.2011.02487.x.

[99] Nakamura M. Clinical significance of autoantibodies in primary biliary cirrhosis. Semin Liver Dis 2014;34:334-340. doi: 10.1055/s-0034-1383732.

[100] Himoto T, Murota M, Yoneyama H, Deguchi A, Kurokochi K, Senda S, et al. Clinical characteristics of patients with autoimmune hepatitis seropositive for anticentromere antibody. Hepatol Res 2010;40:786-792. doi: 10. 1111/j.1872-034X.2010.00684.X.

[101] Al-Chalabi T, Underhill JA, Portmann BC, McFarlane IG, Heneghan MA. Impact of gender on the long-term outcome and survival of patients with autoimmune hepatitis. J Hepatol 2008;48:140-147. doi: 10.1016/j.jhep. 2007.08.013.

[102] Yeoman AD, Westbrook RH, Zen Y, Maninchedda P, Portmann BC, Devlin J, et al. Early predictors of corticosteroid treatment failure in icteric presentations of autoimmune hepatitis. Hepatology 2011;53:926-934. doi: 10. 1002/hep. 24141

[103] Hennes EM, Oo YH, Schramm C, Denzer U, Buggisch P, Wiegard C, et al. Mycophenolate mofetil as second line therapy in autoimmune hepatitis? Am J Gastroenterol 2008;103:3063-3070. doi: 10.1111/j.1572-0241.2008. 02180.x.

[104] Boberg KM, Chapman RW, Hirschfield GM, Lohse AW, Manns MP, Schrumpf $\mathrm{E}$, et al. Overlap syndromes: the International Autoimmune Hepatitis Group 
(IAIHG) position statement on a controversial issue. J Hepatol 2011;54: 374-385. doi: 10.1016/j.jhep.2010.09.002.

[105] Chazouillères O, Wendum D, Serfaty L, Montembault S, Rosmorduc O Poupon R. Primary biliary cirrhosis-autoimmune hepatitis overlap syndrome: clinical features and response to therapy. Hepatology $1998 ; 28$ : 296-301. doi: 10.1002/hep.510280203.

[106] Wang Q, Selmi C, Zhou X, Qiu D, Li Z, Miao Q, et al. Epigenetic considerations and the clinical reevaluation of the overlap syndrome between primary biliary cirrhosis and autoimmune hepatitis. J Autoimmun 2013; 41:140-145. doi: 10.1016/j.jaut.2012.10.004

[107] Yang F, Wang Q, Wang Z, Miao Q, Xiao X, Tang R, et al. The natural history and prognosis of primary biliary cirrhosis with clinical features of autoimmune hepatitis. Clin Rev Allergy Immunol 2016;50:114-123. doi: 10. 1007/s12016-015-8516-5.

[108] Zhang H, Li S, Yang J, Zheng Y, Wang J, Lu W, et al. A meta-analysis of ursodeoxycholic acid therapy versus combination therapy with corticosteroids for PBC-AIH-overlap syndrome: evidence from 97 monotherapy and 117 combinations. Prz Gastroenterol 2015;10:148-155. doi: 10.5114/pg. 2015.51187

[109] Tanaka A, Harada K, Ebinuma H, Komori A, Yokokawa J, Yoshizawa K, et al. Primary biliary cirrhosis - Autoimmune hepatitis overlap syndrome: A rationale for corticosteroids use based on a nation-wide retrospective study in Japan. Hepatol Res 2011;41:877-886. doi: 10.1111/j.1872034X.2011.00844.X.

[110] Loria P, Lonardo A, Leonardi F, Fontana C, Carulli L, Verrone AM, et al. Nonorgan-specific autoantibodies in nonalcoholic fatty liver disease: prevalence and correlates. Dig Dis Sci 2003;48:2173-2181. doi: 10.1023/B: DDAS.0000004522.36120.08

[111] Cotler SJ, Kanji K, Keshavarzian A, Jensen DM, Jakate S. Prevalence and significance of autoantibodies in patients with non-alcoholic steatohepatitis.
J Clin Gastroenterol 2004;38:801-804. doi: $10.1097 / 01 . \mathrm{mcg} .0000139072$. 38580.a0.

[112] Fukuda S, Komori A, Itoh M, Mihara Y, Hashimoto S, Bae SK, et al. Histological remission during corticosteroid therapy of overlapping nonalcoholic steatohepatitis and autoimmune hepatitis: case report and literature review. Case Rep Gastroenterol 2011;5:553-557. doi: 10.1159/000332152.

[113] Sui M, Wu R, Hu X, Zhang H, Jiang J, Yang Y, et al. Low prevalence of hepatitis $B$ virus infection in patients with autoimmune diseases in a Chinese patient population. J Viral Hepat 2014;21:925-929. doi: 10.1111/jvh.12302.

[114] Guidelines for the Prevention, Care and Treatment of Persons with Chronic Hepatitis B Infection. WHO Guidelines Approved by the Guidelines Review Committee. Geneva: WHO Guidelines Approved by the Guidelines Review Committee, 2015.

[115] Wang Q, Sachse P, Semmo M, Lokhande M, Montani M, Dufour JF, et al. T- and B-cell responses and previous exposure to hepatitis B virus in 'anti-HBC alone' patients. J Viral Hepat 2015 22:1068-1078. doi: 10.1111/jvh.12428.

[116] Umemura T, Zen Y, Hamano H, Ichijo T, Kawa S, Nakanuma Y, et al. IgG4 associated autoimmune hepatitis: a differential diagnosis for classical autoimmune hepatitis. Gut 2007;56:1471-1472. doi: 10.1136/gut.2007.122283

[117] Umemura $T$, Zen $\mathrm{Y}$, Hamano $\mathrm{H}$, Joshita $\mathrm{S}$, Ichijo $\mathrm{T}$, Yoshizawa $\mathrm{K}$, et al. Clinical significance of immunoglobulin G4-associated autoimmune hepatitis. J Gastroenterol 2011;46 Suppl 1:48-55. doi: 10.1007/s00535-010-0323-4.

[118] Chung $\mathrm{H}$, Watanabe T, Kudo M, Maenishi O, Wakatsuki $Y$, Chiba T. Identification and characterization of IgG4-associated autoimmune hepatitis. Liver Int 2010;30:222-231. doi: 10.1111/j.1478-3231.2009.02092.X.

[119] Zhao XY, Rakhda MI, Wang TI, Jia JD. Immunoglobulin G4-associated de novo autoimmune hepatitis after liver transplantation for chronic hepatitis B- and C-related cirrhosis and hepatocellular carcinoma: a case report with literature review. Transplant Proc 2013;45:824-827. doi: 10.1016/j.transproceed.2012.02.049. 